\title{
Evaluation of a promising tomato line (Solanum lycopersicum) derived from mutation breeding
}

\author{
ENIK NURLAILI AFIFAH ${ }^{1, \boldsymbol{\bullet}}$, RUDI HARI MURTI ${ }^{\mathbf{1}}$, ADITYA WAHYUDHI ${ }^{2}$ \\ ${ }^{1}$ Department of Agronomy, Faculty of Agriculture, Universitas Gadjah Mada. Jl. Flora No.1, Bulaksumur, Sleman 55281, Yogyakarta, Indonesia. \\ Tel./fax.: +62-274-563062, •email: eniknurlaili21@ugm.ac.id \\ ${ }^{2}$ Department of Agrotechnology, Faculty of Agriculture, Universitas Riau. Jl. Hr. Subrantas Km 12,5, Kampus Bina Widya, Simpang Baru, Panam, \\ Pekanbaru 28293, Riau, Indonesia
}

Manuscript received: 28 January 2021. Revision accepted: 21 March 2021

\begin{abstract}
Afifah EN, Murti RH, Wahyudhi A. 2021. Evaluation of a promising tomato line (Solanum lycopersicum) derived from mutation breeding. Biodiversitas 22: 1863-1868. Tomato (Solanum lycopersicum L.) is a common crop that is widely cultivated and consumed around the world. Demand for tomatoes has increased along with the growth of the human population. Therefore, tomato production has to be continuously developed to meet the ever-rising global demand. Mutation breeding is one of the strategies applied to improve plant yield and quality. This study evaluated a promising mutant breeding line called G6 and compared it to existing varieties. G6 (mutant line), Ratna, Tora, and Intan (commercial varieties) were used as materials and were evaluated for their qualitative and quantitative traits. Overall, G6 showed a slightly flattened fruit shape similar to Ratna. It also had the highest value of locules, long shelf life, and the number of bunches per plant compared to the existing varieties (Ratna, Intan, and Tora). The number of locules is assumed to be linked to fruit size and dimension. Long shelf life is one of the preferred qualities of both consumers and farmers, as it could prevent overmature and rotten tomato fruit during transportation. G6 differed from commercial varieties (Intan, Ratna, and Tora) in terms of the number of locules, shelf life, and the number of bunches per plant.
\end{abstract}

Keywords: Fruit quality, long shelf life, mutation breeding, selection, tomato

\section{INTRODUCTION}

Tomato (Solanum lycopersicum L.) is a commonly cultivated and consumed crop around the world. Tomato has many benefits; it is rich in nutrients, carotenoids, and lycopene and has an abundance of antioxidant compounds (Nkansah et al. 2019). Therefore, the demand for tomatoes in Indonesia and the rest of the world has continued to grow over the years. In relation to this, sustainable tomato production is necessary for supporting the growth of tomato demand globally (Chaudhary et al. 2019). However, the development of techniques for the rapid production of tomato cultivars improved with high-quality fruits remains a challenge. Plant breeding is one of the appropriate ways to increase the national production of tomatoes with highquality fruits (Holme et al. 2019). With the significant growth of our population, it is crucial to improve food production to meet current demands (Fentik 2017).

With the goal of yielding superior traits, plant breeding programs have begun to produce genetic resources that are used as parents or breeding materials (Degefa 2019). One of the rapid strategies to produce such genetic materials is through a mutation breeding program. This kind of breeding program has a good frequency and spectrum of mutation in a short time compared to the conventional crop breeding program (Hossain et al. 2013). For instance, plant breeders could have genetic improvements in many qualitative and quantitative traits, such as high yield (Malek et al. 2012).
Mutation breeding programs provide promising options to enrich the genetic diversity and achieve tomato production improvements (Chaudhary et al. 2019). A mutation breeding is a process of exposing parts of the plant with chemicals or radiations to generate genetic variation to produce cultivars with desired traits (Zakir 2018). Therefore, mutation breeding is an appropriate tool for improving new varieties, and some breeding methods have been explored for the development of genetic resources (Laskar et al. 2018). Currently, over 3200 mutant varieties are officially released and used. Therefore, mutation breeding remains an interesting method in creating plant genetic resources. The advancement of mutation plant breeding further increases the improvement of desired varieties, such as maturity traits, as well as pest and disease resistance, which have important roles in increasing plant yield (Raina et al. 2016). Mutation breeding has been successfully applied since the release of a green mutant tobacco variety derived from the inducedmutant variety in Indonesia (Spencer-Lopes \& Jankuloski 2018). Many other plants have also undergone breeding mutation, including banana, rice, and watermelon (Chaudhary et al. 2019).

In Indonesia, plant breeding researchers at the Faculty of Agriculture, Universitas Gadjah Mada have been developing tomato lines with high yield and good quality though a mutation breeding program. This program mutated the Intan genotype using gamma radiation Cobalt 60 to generate tomato mutants with doses of 20,40, and 60 grays (Hastari et al. 2014) and resulting in various 
morphological and genetic changes in the characteristics of tomato plants. Furthermore, the evaluation of breeding methods has been carried out to select the best plant with high production, plant performance, and high fruit quality until further generations. Selection is one of the crucial parts of the plant breeding method in terms of evaluating the variability of tomato mutants. Jáquez-Gutiérrez et al. (2019) argued that long-term evaluation is essential in selecting mutants altered to have desirable traits, including flower architecture, fruit set, fruit development, and maturation. One promising tomato line has been identified from this program, namely, G6 which has been shown to have high production and good plant performance (Hastari et al. 2014). It also has the potential of being evaluated and compared with existing varieties. Therefore, the current study evaluates G6 traits compared with commercial varieties.

\section{MATERIALS AND METHODS}

\section{General procedures}

This study was carried out at the Horticultural Seed and Agribusiness Development and Promotion Center, Department of Agriculture in Sleman District, Special Region of Yogyakarta, Indonesia. This location has an elevation of 700 asl, average rainfall of approximately $21-100 \mathrm{~mm} / \mathrm{month}$, and a daily temperature of $25^{\circ} \mathrm{C}-4^{\circ} \mathrm{C}$ One mutant line (G6) and commercial varieties (Ratna, Intan, and Tora) were evaluated in this study. G6 is a mutant line generated by the mutation breeding program of the Faculty of Agriculture, Universitas Gadjah Mada, using the seed of Intan genotype mutated with gamma radiation Cobalt 60 with a dose of 40 gray (Hastari et al. 2014). Based on the previous study, G6 was already stable because it was evaluated until M9 generations and can be proposed for the new pure line varieties (Hastari et al. 2014). Ratna and Intan are commercial varieties produced by East-West Seed Indonesia, while Tora is an existing variety produced by the Bogor Agricultural Institute.

This experiment was laid out in a completely randomized block design with subsampling and consisted of 4 replications as blocks and 12 plant samples per genotype per replication. There were 36 plants in each cultivar per block, each planted with a space of $40 \mathrm{~cm} \times 40$ $\mathrm{cm}$. There were 16 beds (width: $1.2 \mathrm{~m}$, length: $10 \mathrm{~m}$, space within beds: $40 \mathrm{~cm}$ ) in the field enriched with organic fertilizer $\left(2 \mathrm{~kg} \cdot \mathrm{m}^{-2}\right)$, Nitrogen, Phosphorus, and Potassium (NPK) with a ratio of $16: 16: 16$ fertilizer $\left(17.5 \mathrm{~g} \cdot \mathrm{m}^{-2}\right)$, and Potassium Chloride (KCL) fertilizer $\left(20 \mathrm{~g}^{\mathrm{m}} \mathrm{m}^{-2}\right)$, and then covered with mulch. Four varieties were shown in the soil medium enriched with organic fertilizer 1:1 (w/w). These plants were transplanted to the field 21 days after germination. The cultivation process carried out in this study included watering, pruning, fertilizing, and harvesting as well as controlling weeds, pests, and diseases.

\section{Data collection}

A total of 12 plants per genotype per replication were observed for qualitative parameters, including plant growth type, leaf attitude, leaf size of leaflets (in middle of leaf), leaf color (upper and lower), seedling anthocyanin, flower color, fruit shape, fruit color (immature), fruit green shoulder (before maturity), fruit color at maturity, fruits color of flesh (at maturity), and fruit size., and quantitative parameters consisting of stem diameter, number of locules, fruit thickness, shelf life, total soluble solid (TSS, ${ }^{\circ}$ brix), vitamin $\mathrm{C}$, fruit weight, number of fruit bunches, total fruit per plant, and yield per ha). The qualitative parameters (e.g., morphological traits) were observed according to the tomato UPOV guidelines (2019). The measurement of shelf life was obtained by measuring the number of fruit days elapsed from the harvesting time until the first symptom of deterioration while the fruit remains soft. In order to determine this parameter, tomato fruits were stored in boxes in single layers at $25{ }^{\circ} \mathrm{C} \pm 3{ }^{\circ} \mathrm{C}$, after which they were observed every two days.

Five fruits per plant were taken for measuring fruit qualities. Tomatoes were cut into two slices to measure pericarp thickness ( $\mathrm{mm}$ ) and locules per fruit. Then, the cut tomatoes were used to record TSS ( ${ }^{\circ}$ brix) using a hand refractometer. Furthermore, vitamin $\mathrm{C}$ content was analyzed using titrimetic method based on Das et al. (2019). All collected data were analyzed using analysis of variance (ANOVA) and continued with Tukey HSD's test at $\alpha=5 \%$.

\section{RESULTS AND DISCUSSION}

\section{Qualitative characters}

The plant performances of the selected mutant line and existing varieties considering qualitative parameters are presented in Table 1. Tomato mutant G6 showed the same determinate plant growth compared to the commercial varieties (Ratna, Intan, and Tora). G6 also had the same leaf attitude, leaf size of leaflets (in middle of leaf), leaf color (upper and lower), seedling anthocyanin, flower color, fruit color (immature), fruit color at maturity, fruit color of flesh (at maturity), and fruit size. However, G6 had a different fruit shape compared to Tora, which showed an obovate fruit shape. In contrast, G6 had a slightly flattened fruit shape.

As shown in Figure 1, G6 had the same color of immature and mature fruits compared to the commercial varieties. The color of immature fruits was light green marked with an absence of green shoulder due to the lower amount of chlorophyll pigments produced. The mature fruit and fruit color of flesh of G6 had a orange color similar to Ratna, Intan, and Tora. It is widely known that fruit color is the most essential and complex attribute of tomato fruit quality.

\section{Shelf-life performances}

As shown in the histogram in Figure 2, Ratna had the longest shelf life (27 days) followed by G6 with 26 days. This value was not statistically significantly different, indicating that G6 had the same shelf life compared to Ratna, but had a statistically significantly different shelf life compared to Intan and Tora. Therefore, G6 has a longer shelf life than existing varieties (Intan and Tora). 
Table 1. Qualitative characters of G6 and three commercial varieties

\begin{tabular}{|c|c|c|c|c|}
\hline \multirow{2}{*}{ Variables } & \multicolumn{4}{|c|}{ Varieties } \\
\hline & G6 (Mutant line) & Ratna & Intan & Tora \\
\hline Plant growth type & Determinate & Determinate & Determinate & Determinate \\
\hline Leaf attitude & Semi-erect & Semi-erect & Semi-erect & Semi-erect \\
\hline Leaf size of leaflets (in middle of leaf) & Medium* & Medium* & Medium* & Medium* \\
\hline Leaf color (upper) & Green & Green & Green & Green \\
\hline Leaf color (lower) & Dark green & Dark green & Dark green & Dark green \\
\hline Seeding anthocyanin & Absence (green) & Absence (green) & Absence (green) & Absence (green) \\
\hline Flower color & Yellow & Yellow & Yellow & Yellow \\
\hline Fruit shape & Slightly flattened & Slightly flattened & Slightly flattened & Obovate \\
\hline Fruit color (immature) & Light green & Light green & Light green & Light green \\
\hline Fruit green shoulder (before maturity) & Absence & Absence & Absence & Absence \\
\hline Fruit color at maturity & Orange & Orange & Orange & Orange \\
\hline Fruit color of flesh (at maturity) & Orange & Orange & Orange & Orange \\
\hline Fruit size & Medium* & Medium* & Medium* & Medium* \\
\hline
\end{tabular}

Note: Morphological characterization was based on the tomato UPOV guidelines (2019). (*): Sizes and pictures were based on the tomato UPOV guidelines.

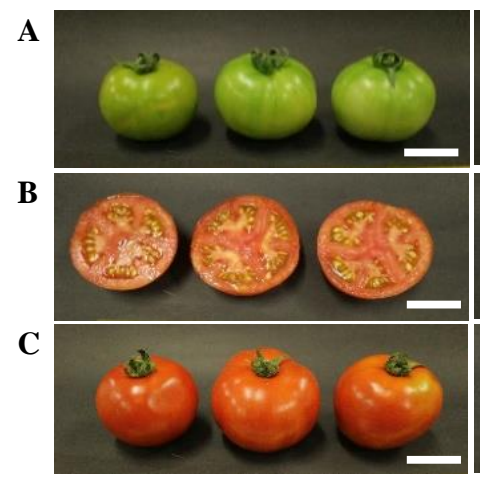

G6

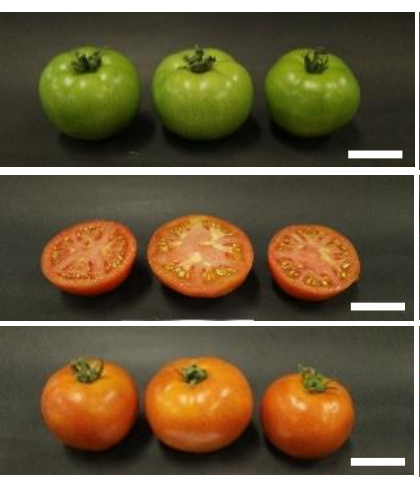

Ratna

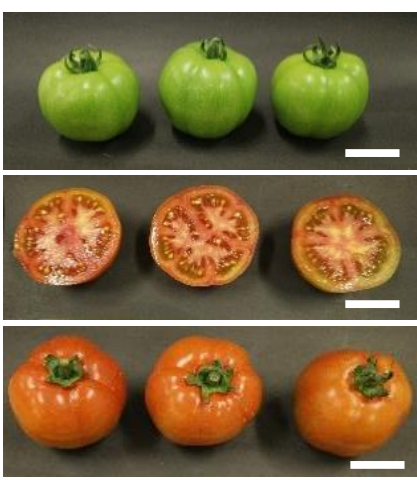

Intan

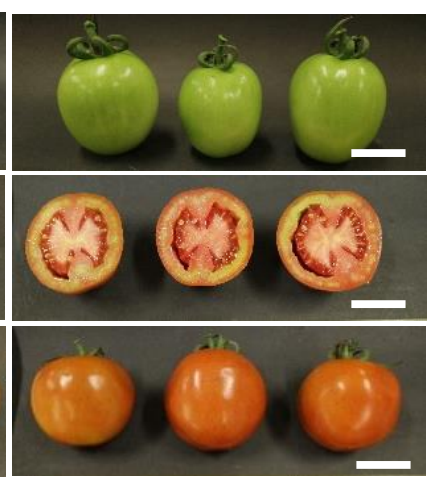

Tora

Figure 1. Fruit color of mutant line and commercial varieties: A. Immature fruits; B. Fruit flesh at maturity and locules; C. Mature fruits. $\mathrm{Bar}=3 \mathrm{~cm}$

\section{Fruit performances}

Data on TSS, vitamin C content, number of locules, and fruit thickness are presented in Table 2. As shown in the table, G6 and existing varieties did not have significantly different TSS contents. G6 had a high value of TSS quality, but it was not significantly different from other varieties. The highest value of vitamin $\mathrm{C}$ was found in Intan, followed by Tora, Ratna, and G6. The results revealed that G6 did not have a significant level of vitamin C compared to Ratna and Tora. In addition, G6, Ratna, and Intan had the same number of locules. In contrast, Tora had the lowest number of locules per fruit. Furthermore, the highest fruit pericarp thickness was found in Tora, followed by Intan and Ratna. G6 had a fruit pericarp thickness of 4.7 $\mathrm{cm}$.

\section{Yield performances}

Data on stem diameter, the number of fruits per bunches, the number of bunches per plant, and yield are presented in Table 2. The data showed that G6 had a high stem diameter at around $14.11 \mathrm{~cm}$, although this was not significantly different from those of Ratna and Intan. In comparison, the stem diameter of G6 was statistically different compared to Tora. The highest number of fruits per bunches was observed in Tora, followed by Intan. In contrast, the lowest number of fruits per bunches was found in G6 and Ratna. G6 and Tora had a high number of bunches per plant, whereas Ratna and Intan had the lowest number of bunches per plant. Fruit weight data showed that Intan had a high value at $162.49 \mathrm{~g}$, whereas G6 had a fruit weight of around $94.71 \mathrm{~g}$. Tora and Intan both had higher yields compared to Ratna and Intan. Meanwhile, G6 and Ratna had the same yield at around $16.5 \mathrm{~kg}$. ha- ${ }^{-1}$.

\section{Discussion}

This study evaluated the morphological characteristics of a promising tomato mutant compared to the commercial varieties to determine whether the mutant line had good, comparable characteristics as those of commercial varieties. The observations were based on the tomato UPOV tomato guidelines (2019). Overall, G6 had a slightly flattened fruit shape similar to Ratna and Intan. In contrast, Tora had an obovate fruit shape that was different from G6. Based on Laskar et al. (2018), tomato mutation breeding 
has led to various traits of tomatoes, including fruit shape and size. Therefore, the morphological characterization of fruit shape must be carried out to determine the special trait of a particular variety. Casals et al. (2019) reported that consumers generally preferred tomato fruits with a taste ideotype and have a high variability of chemical composition in terms of fruit shape and plant performance. According to Renna et al. (2019), morphological characterization is useful, as it enables plant breeders to develop traditional cultivars without losing their particular trait.

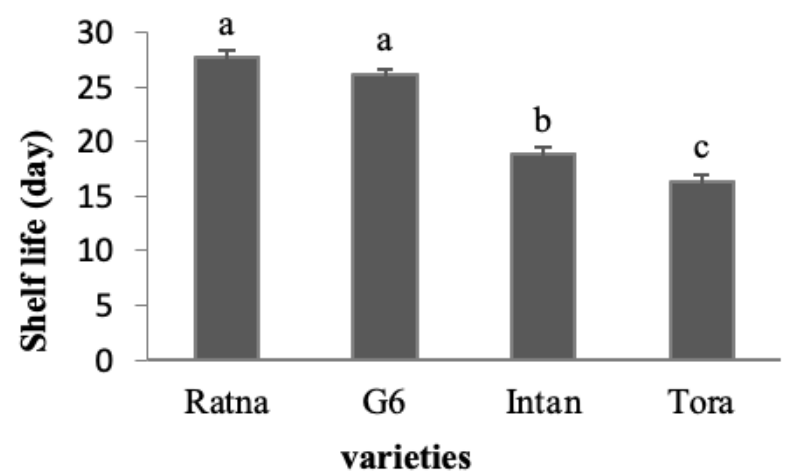

Figure 2. Histogram of the shelf life of the tomato mutant (G6) and each commercial variety. Note: Bars followed with same letters are not significantly different based on Tukey's HSD test at $\alpha=5 \%$.

Table 2. Quantitative characters in mutant line compared to the commercial varieties

\begin{tabular}{lcccc}
\hline Varieties & $\begin{array}{c}\text { TSS } \\
(\mathbf{m g} / \mathbf{1 0 0} \\
\mathbf{g})\left({ }^{\circ} \mathrm{brix}\right)\end{array}$ & $\begin{array}{c}\text { Vitamin } \\
\mathbf{C} \\
(\mathbf{m g} / \mathbf{1 0 0} \\
\mathbf{g})\end{array}$ & $\begin{array}{c}\text { Number } \\
\text { of locules }\end{array}$ & $\begin{array}{c}\text { Fruit } \\
\text { pericarp } \\
\text { thickness } \\
(\mathbf{c m})\end{array}$ \\
\hline $\begin{array}{l}\text { G6 } \\
\text { (mutant) }\end{array}$ & $5.23 \mathrm{a}$ & $20.51 \mathrm{~b}$ & $4 \mathrm{a}$ & $4.7 \mathrm{c}$ \\
Ratna & $4.60 \mathrm{a}$ & $20.92 \mathrm{~b}$ & $4 \mathrm{a}$ & $5.18 \mathrm{bc}$ \\
Intan & $4.98 \mathrm{a}$ & $34.07 \mathrm{a}$ & $4 \mathrm{a}$ & $5.88 \mathrm{ab}$ \\
Tora & $4.77 \mathrm{a}$ & $25.31 \mathrm{~b}$ & $2 \mathrm{~b}$ & $6.49 \mathrm{a}$ \\
\hline
\end{tabular}

Note: Numbers followed with the same letters are not significantly different at Tukey's HSD test at $\alpha=5 \%$.

Table 3. Quantitative characters of the mutant line compared to the three commercial varieties

\begin{tabular}{lccccc}
\hline Varieties & $\begin{array}{c}\text { Stem } \\
\text { diameter } \\
(\mathbf{c m})\end{array}$ & $\begin{array}{c}\text { Number } \\
\text { of fruits } \\
\text { per } \\
\text { bunches }\end{array}$ & $\begin{array}{c}\text { Number } \\
\text { of } \\
\text { bunches } \\
\text { per plant }\end{array}$ & $\begin{array}{c}\text { Fruit } \\
\text { weight } \\
(\mathbf{g})\end{array}$ & $\begin{array}{c}\text { Yield } \\
(\mathbf{k g} \text {. ha }\end{array}$ \\
\hline $\mathbf{1})$
\end{tabular}

Note: Numbers followed with the same letters are not significantly different at Tukey's HSD test at $\alpha=5 \%$.
Holme et al. (2019) explained that mutation plant breeding is random and could not select the target genes. Therefore, it needs to be partially directed by mapping genes to select the target traits. Furthermore, this material could be combined with another line to generate the elite lines. For the trait of mature and immature fruit type, G6 showed the same fruit color and performance compared to the commercial varieties. Furthermore, G6 showed an immature fruit with red-orange color and the absence of green shoulder. The latter trait is considered a desirable improvement of fruit quality, because having a green shoulder inhibits fruit maturity and results in imperfect fruit color. Tomato fruit color is related to the diverse carotenoid pigment system and is conditioned by pigment types and concentration. This condition is caused by genetics and the environment (Rawal et al. 2016).

In the current study, G6 showed a longer shelf life compared to existing varieties (i.e., Intan and Tora). Furthermore, Fentik (2017) pointed out that consumers and farmers are interested in the tomato fruit with a long shelf life and ripening period. Plant breeding programs aim to modify plants by endowing them with superior traits, such as mechanical harvesting, resistance against pests and diseases, and good fruit quality (including better taste, flavor, and long shelf life) to solve farmers' problems and meet growing consumer demand (Tiwari 2017). According to Zhang et al. (2013), tomato shelf life is an important trait quality for farmers and consumers. In order to resolve the problem of having overmature fruits during transportation, farmers usually pick tomatoes when they are still firm and green, keep them at low temperatures, and prime them with ethylene. However, this strategy has a negative effect on the flavor, texture, and tomato aroma. Therefore, developing a tomato variety with long shelf life is essential in producing high-quality tomatoes.

Meanwhile, TSS is related to tomato acidity (Renna et al. 2019). Tomato sweetness and acidity are popular customer preferences (Fentik 2017). For example, some people prefer tomatoes with a high level of sweetness than acidic tomatoes, while other prefer tomatoes with a medium level of acidity. In our results, we found that G6 had a TSS value of 5.23. A study by Casals et al. (2018) showed that fresh market tomatoes had an average TSS level of 4.3. At the same time, some consumers prefer the highest level of sweetness found in cherry tomatoes, which are ideal for salads and other diet-friendly dishes. Therefore, cherry tomatoes are usually eaten directly and have a high level of sweetness. As a result, tomatoes used as a vegetable should not be as sweet as a cherry tomato. Renna et al. (2019) also reported that acidity is an essential attribute to consider in processing tomato fruit. The higher the level of acidity, the easier it is to control microbial degradation in processing tomato products.

Vitamin $\mathrm{C}$ is another interesting trait that must be elevated by plant breeders, because many consumers prefer to eat tomatoes with a high vitamin $\mathrm{C}$ content (Valsikova et al. 2017). In accordance with our results, G6 had a lower level of vitamin $\mathrm{C}$ than the Intan variety. Furthermore, according to Stevens et al. (2007) ascorbic acid in tomatoes is controlled by several QTL. This study evaluated the 
vitamin $\mathrm{C}$ content in several tomato mutant variants, and the results showed that many of them contained reduced vitamin $C$. Improving the amount of vitamin $C$ in tomatoes remains a challenge to this day and may thus be a target of future plant breeding programs.

Meanwhile, there was also a significant difference between G6 and Tora in terms of the number of locules. G6, Ratna, and Intan had four locules, whereas Tora only had two locules per fruit. This finding indicated that the number of locules can be considered one of the essential characteristics of tomato fruits. According to many studies, this is declared that the number of locules is associated with fruit dimension and size $(\mathrm{Mu}$ et al. 2017). For example, Chu et al. (2019) reported that many locules often lead to an enlarged fruit. Thus, this trait can be controlled genetically in order to produce enlarged tomatoes with many locules. In terms of fruit pericarp thickness, Tora and Intan showed high fruit thickness values at approximately 6.49 and $5.88 \mathrm{~cm}$, respectively. Based on statistical analysis, G6 had the lowest fruit thickness at around 4.7 $\mathrm{cm}$, which was significantly different from those of Tora and Intan.

Generally, some tomatoes have a medium stem with anthocyanin, while others have an absence of stem anthocyanin. Therefore, stem diameter is one of the specific characteristics of tomato plants that must be observed. In our study, G6 had a high stem diameter and number of fruits per bunches at around $14.11 \mathrm{~cm}$ and 3.79, respectively, which were statistically different compared to those of Intan and Tora. G6 also had the highest number of bunches per plant at around 7.41. At the same time, G6 showed low fruit weight and yield at around $94.71 \mathrm{~g}$ and $16.479 \mathrm{~kg}$. respectively. These results indicated that G6 had a medium fruit size. Hence, such quality must be improved to increase fruit size and productivity, which can overcome consumer and farmer demands in the future. Chaudhary et al. (2019) indicated that most mutant lines carry a recessive mutation, although this does not affect their phenotypes. Therefore, mutant lines must be evaluated to find the homozygous mutant population with good traits. Holme et al. (2019) reported that mutation breeding resulted in several morphological variations. Therefore, the mutant line may be crossed with another line to combine their superior traits and then use them further as breeding materials.

In conclusion, the mutant tomato (G6) differed from commercial varieties (Intan, Ratna, and Tora) in terms of the number of locules, shelf life, and the number of bunches per plant. However, all varieties showed the same qualitative traits, including leaf attitude, leaf size of leaflets (in middle of leaf), leaf color (upper and lower), seedling anthocyanin, flower color, fruit color (immature), fruit color at maturity, fruit color of flesh (at maturity), and fruit size. The number of locules is important in differentiating among the varieties. Furthermore, having a long shelf life is essential, because such a trait could prevent overmature and rotten tomatoes during transportation. Therefore, most plant breeding programs must aim to improve tomato plants by developing variants with a long shelf life.

\section{ACKNOWLEDGEMENTS}

The authors would like to thank the Department of Agronomy, Faculty of Agriculture, Universitas Gadjah Mada, Yogyakarta, Indonesia for funding and supporting this research.

\section{REFERENCES}

Casals J, Rivera A, Sabaté J, Romero del Castillo R, and Simó J. 2019. Cherry and fresh market tomatoes: Differences in chemical, morphological, and sensory traits and their implications for consumer acceptance. Agronomy 9 (1): 9. DOI: 10.3390/agronomy9010009

Chaudhary J, Alisha A, Bhatt V, Chandanshive S, Kumar N, Mir Z, Kumar A, Yadav SK, Shivaraj SM, Sonah H, Deshmukh R. 2019. Mutation breeding in tomato: Advances, applicability, and challenges. Plants 8 (5): 128. DOI: 10.3390/plants8050128

Chu YH, Jang JC, Huang Z, Knaap E. 2019. Tomato locule number and fruit size controlled by natural alleles of lc and fas. Plant Direct 3 (7): e00142. DOI: $10.1002 /$ pld3.142.

Das I, Hazra P, Longjam M, Bhattacharjee T, Maurya PK, Banerjee S, and Chattopadhyay A. 2019. Characterization of induced mutants and their hybrids of tomato (Solanum lycopersicum L.) for growth, yield and fruit quality traits to explore the feasibility in future breeding. Genet Resour Crop Evol 66: 1421-1441. DOI: 10.1007/s10722-019-00806-5

Degefa I. 2019. Plant breeding methods: In brief for student. Intl J Agric Agribusiness 3: 156-203.

Fentik DA. 2017. Review on genetics and breeding of tomato (Lycopersicon esculentum Mill). Adv Crop Sci Tech 5: 306. DOI: 10.4172/2329-8863.1000306

Hastari RP, Ambarwati E, Murti RH. 2014. Evaluation of genetic and environment interaction of six promising mutant tomato lines (Lycopersicon esculentum) in low land and high land. Vegetalika 3: 63-76.

Holme IB, Gregersen PL, Brinch-Pedersen H. 2019. Induced genetic variation in crop plants by random or targeted mutagenesis: Convergence and differences. Front Plant Sci 10:1468. DOI: 10.3389/fpls.2019.01468

Hossain MS, Ashrafuzzaman M, Malek MA, Mondal MMA, Rafii MY, Ismail MR, Islam MS. 2013. Evaluation and selection of tomato mutants for cultivation in Summer. Res Crops 14: 546-550.

Jáquez-Gutiérrez M, Atarés A, Pineda B, Angarita P, Ribelles C, Garciasogo B, Sánchez-López J, Capel C, Yuste-Lisbona FJ, Lozano R, Moreno V. 2019. Phenotypic and genetic characterization of tomato mutants provides new insights into leaf development and its relationship to agronomic traits. BMC Plant Biol 19 (1): 141. DOI: 10.1186/s12870-019-1735-9

Laskar RA, Chaudhary C, Khan S, Chandra A. 2018. Induction of mutagenized tomato populations for investigation on agronomic traits and mutant phenotyping. J Saudi Soc Agric Sci 17: 51-60. DOI: 10.1016/j.jssas.2016.01.002

Laskar RA, Laskar, AA, Raina A, Khan S, and Younus H. 2018. Induced mutation analysis with biochemical and molecular characterization of high yielding lentil mutant lines. Int J Biol Macromolecule 109: 167179. DOI: 10.1016/j.ijbiomac.2017.12.067

Malek MA, Begum HA, Begum M, Sattar MA, Ismail MR, Rafii, MY. 2012. Development of two high yielding mutant varieties of mustard [Brassica juncea (L.) Czern \& Coss] through gamma rays-irradiation. Aust J Crop Sci 6: 922-927.

Mu Q, Huang Z, Chakrabarti M, Illa-Berenguer E, Liu X, Wang Y, van der Knaap E. 2017. Fruit weight is controlled by cell size regulator encoding a novel protein that is expressed in maturing tomato fruits. PLoS Genet 13 (8): e1006930. DOI: 10.1371/journal.pgen.1006930

Nkansah GO, Blay ET, Asante IK, Ochar K. 2019. Evaluation of selected tomato (Solanum lycopersicum L.) cultivars in Ghana for superior fruit yield and yield component traits. J Hortic 6: 262.

Raina A, Laskar RA, Khursheed S, Amin R., Tantray YR, Parveen K, Khan S. 2016. Role of mutation breeding in crop improvement-past, present, and future. Asian Res J Agric 2 (2): 1-13. DOI: 10.9734/ARJA/2016/29334. 
Rawal R, Gautam DM, Khadka R, Gautam I, Mishra K, Acedo A, Hanson W, Easdown J, Hughes A, and Keatinge J. 2016. Fruit quality characters of tomato (Solanum lycpersicum L.) genotypes differed by maturity stages. $5^{\text {th }}$ International Conference on Agriculture, Environment and Biological Sciences (ICAEBS-16), Pattaya, 28-29 April 2016. [Thailand]

Renna M, D'Imperio M, Gonnella M, Durante M, Parente A, Mita G, Santamaria P, Serio F. 2019. Morphological and chemical profile of three tomato (Solanum lycopersicum L.) landraces of a semi-arid Mediterranean environment. Plants (Basel) 8 (8): 273. DOI: 10.3390/plants8080273

Spencer-Lopes, Jankuloski L. 2018. Manual on Mutation Breeding, Vienna Austria.

Stevens R, Buret M, Duffé P, Garchery C, Baldet P, Rothan C, Causse M. 2007. Candidate genes and quantitative trait loci affecting fruit ascorbic acid content in three tomato populations. Plant Physiol 143: 1943-1953. DOI: $10.1104 /$ pp.106.091413
Tiwari A. 2017. Plant breeding: A prospect in developing world. EC Microbiol 8: 272-278.

UPOV (International Union for the Protection of New Varieties of Plants) for Tomato. 2019. https://www.upov.int/portal/index.html.en.

Valsikova M, Komár P, and Rehuš M. 2017. The effect of varieties and degree of ripeness to vitamin $\mathrm{C}$ content in tomato fruits. Acta Horticulturae et Regiotecturae 20: 44-48.

Zakir M. 2018. Mutation breeding and its application in crop improvement under current environmental situations for biotic and abiotic stresses. Int $J$ Res Stud Agric Sci 4: 1-10. DOI: 10.20431/2454-6224.0404001

Zhang Y, Butelli E, Stefano RD, Schoonbeek H, Magusin A, Pagliarani C, Wellner N, Hill L, Orzaez D, Granell A, Jones JDG,6 and Martin C. 2013. Anthocyanins double the shelf life of tomatoes by delaying overripening and reducing susceptibility to gray mold. Curr Biol 23 (12): 1094-1100. DOI: 10.1016/j.cub.2013.04.072 